\section{$\underset{\substack{\text { hommes } \\ \text { \& migrations }}}{ }$}

\section{Hommes \& migrations}

Revue française de référence sur les dynamiques

migratoires

$1334 \mid 2021$

Exposer le racisme et l'antisémitisme

\title{
Blaise Ndala, Dans le ventre du Congo
}

Paris, Seuil, 2021, 368 p., $20 €$.

\section{Valérie Pillet-Dziedzicki}

\section{(2) OpenEdition}

\section{Journals}

\section{Édition électronique}

URL : https://journals.openedition.org/hommesmigrations/13178

DOI : 10.4000/hommesmigrations. 13178

ISSN : 2262-3353

\section{Éditeur}

Musée national de l'histoire de l'immigration

\section{Édition imprimée}

Date de publication : 1 juillet 2021

Pagination : 235-236

ISBN : 978-2-919040-58-2

ISSN : $1142-852 X$

\section{Référence électronique}

Valérie Pillet-Dziedzicki, «Blaise Ndala, Dans le ventre du Congo », Hommes \& migrations [En ligne],

1334 | 2021, mis en ligne le 01 juillet 2021, consulté le 04 février 2022. URL : http://

journals.openedition.org/hommesmigrations/13178; DOI : https://doi.org/10.4000/

hommesmigrations. 13178 


\section{Dans le ventre du Congo}

Blaise Ndala, Paris, Seuil, 2021, 368 p., $20 €$

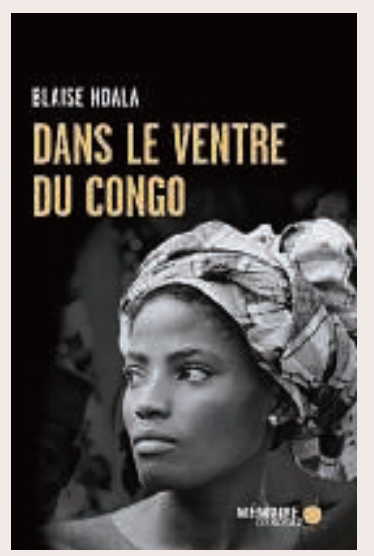

Tshala est une étudiante modèle au pensionnat de l'école SainteMarie de la Miséricorde. Quand, en cette fin d'année 1957, elle rencontre René Comhaire, l'administrateur belge du district, c'est le coup de foudre. Mais cet amour impossible entre un homme blanc, représentant du Royaume de Belgique colonial, et une femme noire, fille du roi des Bakuba promise au prince des Lunda, ne durera que peu de temps et, très vite, les deux amants seront séparés.

On ne sait que peu de choses de René, et surtout de ce qu'il est devenu. Ce que nous en dit Blaise Ndala, c'est qu'il est un notable amoureux de l'Afrique et issu d'une famille liée de longue date à ce continent. Tshala, elle, est une jeune femme de 18 ans, d'une beauté éblouissante et d'une grande pureté d'âme, qui rêve de vivre sa vie et n'entend pas sacrifier son bonheur à la tradition.

Quarante-cinq ans plus tard, Nyota, nièce de Tshala, arrive en Belgique pour y poursuivre ses études. Elle compte aussi mener à bien une quête, celle de faire la lumière sur l'histoire de sa tante disparue en 1958. Cette quête est primordiale pour l'histoire de sa famille, pour que la tradition ne soit pas rompue. Elle est aussi vitale pour Nyota qui, pour savoir où elle va, a besoin de comprendre d'où elle vient.

Dès sa séparation d'avec René, le destin de Tshala bascule. Devenue la proie d'un «ami» de René, elle doit fuir pour sauver sa vie et se retrouve prise au cœur d'un piège qui l'emmènera jusqu'en Belgique, dans le «village congolais» de l'Exposition universelle de 1958.

Pourtant, un «village congolais», Robert Dumont, le souscommissaire de l'exposition, n'en voulait pas, mais son opposition n'a pu faire face à la volonté royale. Quarante-cinq ans plus tard, son fils Francis, qui très tôt a coupé les ponts avec son père, rencontrera Nyota. Tous deux tenteront de découvrir les secrets emportés par leurs aïeux.

À travers l'histoire de Tshala, Blaise Ndala dénonce les exactions coloniales, les viols, les vols, les trafics. Il décrit la richesse du Congo, ses différents royaumes bafoués par les colons belges, son art et sa culture Kuba. Il rend hommage à Patrice Lumumba, future grande figure de l'Indépendance du Congo derrière laquelle on aperçoit l'ombre d'un jeune journaliste, Joseph-Désiré Mobutu. Il évoque Antoine Wendo Kolosoy, le père de la rumba congolaise, idole de toute une génération.

Dans la Belgique contemporaine, Blaise Ndala dénonce le racisme. Le racisme rencontré par Nyota, hôtesse lors d'un salon automobile, qui fait écho au racisme enduré par sa tante quarante-cinq ans plus tôt; le racisme des supporters qui gangrène le football, à travers les insultes qui résonnent dans le stade du Heysel, ce même stade qui accueillit la première finale européenne de football jouée en Belgique entre le Real de Madrid et l'AC Milan à l'occasion de l'Exposition universelle de 1958.

En 2003, Blaise Ndala, récemment arrivé en Belgique pour y poursuivre ses études, visite le Musée royal d'Afrique centrale et découvre alors 
l'existence de sept sépultures d'hommes et de femmes exhibés lors de l'Exposition universelle de 1897 et qui en sont morts, terrassés par les maladies. Cette expérience suscite chez l'auteur la volonté de redonner une vie à ces inconnus à travers l'écriture d'un roman.

Ce roman prendra pour cadre l'Exposition universelle de 1958, où les «figurants» du «village congolais», excédés par le comportement des visiteurs, ont décidé de quitter l'exposition.

Alors, même si l'Exposition universelle de 1958 n'est pas l'exposition coloniale de 1931, le Musée royal d'Afrique centrale n'est pas le Palais de la Porte Dorée, ce que Blaise Ndala montre à travers les yeux de Tshala et Nyota défie le temps et les lieux pour parler à chacun d'entre nous de ce passé colonial dont nous sommes tous les héritiers.

Valérie Pillet-Dziedzicki, membre du comité de lecture du Prix littéraire de la Porte Dorée. 